\title{
Risk Factors for Anterior Cortical Impingement of Short Cephalomedullary Nail in Chinese Elderly Patients with Intertrochanteric Fracture
}

This article was published in the following Dove Press journal:

Therapeutics and Clinical Risk Management

\author{
Shaobo Nie* \\ Ming Li* \\ Jiantao Li (D) \\ Yanpeng Zhao \\ Xiang Cui \\ Gaoxiang Xu \\ Licheng Zhang \\ Wei Zhang \\ Peifu Tang $(\mathbb{D}$
}

Department of Orthopedics, The First Medical Centre, Chinese PLA General Hospital, National Clinical Research

Center for Orthopedics, Sports Medicine

\& Rehabilitation, Beijing 100853, People's

Republic of China

*These authors contributed equally to this work
Correspondence: Wei Zhang; Peifu Tang Department of Orthopedics, The First Medical Centre, Chinese PLA General Hospital, National Clinical Research Center for Orthopedics, Sports Medicine \& Rehabilitation, Beijing 100853, People's Republic of China

Tel +86-I0-682I 2342

Email bszw@hotmail.com;

pftang30I@I63.com
Background: Anterior cortical impingement is a common phenomenon after intramedullary fixation in Asian patients with intertrochanteric fractures. It may cause thigh pain and even fracture of the femoral shaft, which may seriously affect postoperative rehabilitation and limb function of patients. However, little was known about risk factors for anterior cortical impingement in Chinese elderly after intramedullary nailing. Hence, the aim of this study was to certify the risk factors for anterior cortical impingement treated with intramedullary nails of intertrochanteric fracture, hoping to provide suggestions for surgical treatment.

Patients and Methods: A retrospective consecutive series of 94 patients who had been diagnosed as intertrochanteric fracture at our institution was included from January 2019 to November 2019. All patients were treated with intramedullary fixation and followed up for at least 6 months. Demographic, surgical and anesthesiologic information, as well as radiographic data and complications were collected and reviewed.

Results: The ratio of anterior cortical impingement is significantly higher in female patients than that of males $(80.4 \%$ vs $18.6 \%, P=0.041)$. Higher incidence of anterior cortical impingement was found in the longer intramedullary nail group, especially in females. Gender (as a female patient) and length of nail were significant risk factors for anterior cortical impingement in intertrochanteric fracture patients treated with intramedullary nail $(\mathrm{OR}=2.662,95 \% \mathrm{CI}=1.010-7.018, P=0.447$; $\mathrm{OR}=1.047,95 \% \mathrm{CI}=1.016-1.079$, respectively). The length of nail was a risk factor for anterior cortical impingement in female intertrochanteric fracture patients treated with intramedullary nail $(\mathrm{OR}=1.051,95 \% \mathrm{CI}=1.015-1.089)$.

Conclusion: Elderly female patients with intertrochanteric fractures treated with intramedullary nails had a higher incidence of anterior cortical impingement. The length of short intramedullary nail is a risk factor for anterior cortical impingement. Patients with anterior cortical impingement may suffer serious complications.

Keywords: anterior cortical impingement, intramedullary nail, risk factors, intertrochanteric fracture

\section{Introduction}

Femoral intertrochanteric fractures affect patients from middle old-age, especially the elderly. Because of severe osteoporosis, it is very prone to be caused by lowenergy trauma. ${ }^{1}$ As the population aging intensifies, the incidence of intertrochanteric fractures increased year by year. There are estimated to be 6.26 million fractures worldwide by 2050, and half of them in Asia. ${ }^{2}$ Traditional bedridden conservative treatment may lead to high incidence of complications and mortality 
due to immobilization. ${ }^{3,4}$ In order to enable patients to get out of bed early, surgical treatment is essential.

At present, intramedullary nailing under fluoroscopy has become the standard treatment for intertrochanteric fractures due to its good mechanical properties and minimally invasive procedure, ${ }^{5}$ especially in unstable fractures. However, with the increase of intramedullary nail application, the number of implant failures has also increased gradually, which was reported to be up to $20.5 \%{ }^{6}$ As one of the common complications, cortical impingement caused by the over contact of the tip of the nail and the femoral cortex may often lead to thigh pain and even fractures of the femoral shaft, which seriously affect postoperative rehabilitation and limb function of patients. ${ }^{7,9}$ Previous studies have reported a higher incidence in the Asian population, ${ }^{10}$ which may be attributed to the differences of bone morphology and mismatch of implant. As it is well known, Asian femurs are smaller than Caucasian and have a larger anterior bow. ${ }^{11}$ As a result, the Asian type of proximal femoral nail antirotation (PFNA) has become the first choice of treatment. ${ }^{12}$ However, the cortical impingement remains problematic, especially for short nails less than $240 \mathrm{~mm}$. Chang et $\mathrm{al}^{13}$ had reported that nearly $40 \%$ of Chinese patients had the phenomenon of anterior cortical impingement. Whereas little has been known about risk factors for anterior cortical impingement in Chinese elderly intertrochanteric fracture patients stabilized with an intramedullary nail. Therefore, we retrospectively analyzed a group of patients with intertrochanteric fractures treated by intramedullary nailing in our hospital, to explore the risk factors for the anterior cortical impingement, hoping to provide a suggestions for surgical treatment.

\section{Patients and Methods}

\section{Subjects}

A retrospective review of consecutive patients who had been diagnosed as intertrochanteric fracture (International Classification of Diseases, 9th edition, code: 820) at our institution was conducted from January 2019 to November 2019. One-hundred and thirty patients were included, with 46 males and 84 females. The inclusion criteria was that diagnosed as intertrochanteric fractures by X-ray or CT, and the fractures were caused by low-energy trauma. The exclusion criteria included: 1) patients were under the age of 50,2) patients with the surgical contraindications but no surgical treatment was performed, 3) patients were not treated with intramedullary nail, 4) patients had malignancy, rheumatoid arthritis, metabolic bone disease, or other non-osteoporotic fractures, 5) patients died within half a year after the operation and did not complete the follow-up, and 6) patients were reluctant to participate in studies or lost to follow-up. Based on the criteria above, 94 patients were finally included in the study (Figure 1).

\section{Operation of Intramedullary Nailing}

Patients were operated on in supine position on a radiolucent traction fracture table. All patients received a single dose of $1,500 \mathrm{mg}$ cefuroxime 30 minutes prior to surgery as antibiotic prophylaxis. The procedures were performed under fluoroscopy guidance. Patients underwent closed reduction with the assistance of a traction table and closed manipulation techniques. After routine skin preparation and draping, the guide wire was inserted from the tip of the greater trochanter, followed by reaming of the proximal femur. If the satisfactory reduction failed to be achieved by a closed maneuver, a limited incision would be made for mini-open reduction with reduction instruments. Cephalomedullary nails of the optimal length, selected according to the preoperative planning, were inserted into the femoral medullary cavity. A distal locking screw was inserted under the guidance of the nail specification. The fracture and implant position were checked by fluoroscopy. No additional fixations were necessary. Dynamic fixation for all distal screws was performed under the guidance of the target arm.

\section{Radiographic Measurements}

The position of the axial extension line of the intramedullary nail in the femoral medullary cavity was measured on the lateral view. The first $1 / 3$ from the anterior to the posterior was defined as anterior, the middle was defined as median, and the last $1 / 3$ was defined as posterior. ${ }^{8}$ Subsequently, in the CT imaging data, the layer just disappeared at the end of the intramedullary nail was determined in the horizontal position of the femoral marrow cavity. At the upper level of this layer, the medullary cavity was divided into three equal parts from anterior to posterior. If the end of the nail was located anteriorly, that was recorded as anterior. The anterior and posterior was defined as cortical impingement, while the middle of the medullary cavity was defined as match. According to the definition above, patients were divided into the impinged and matched group.

\section{Data Collection}

Clinical parameters, such as age, gender, height, weight, body mass index (BMI), type of internal fixation, ASA 


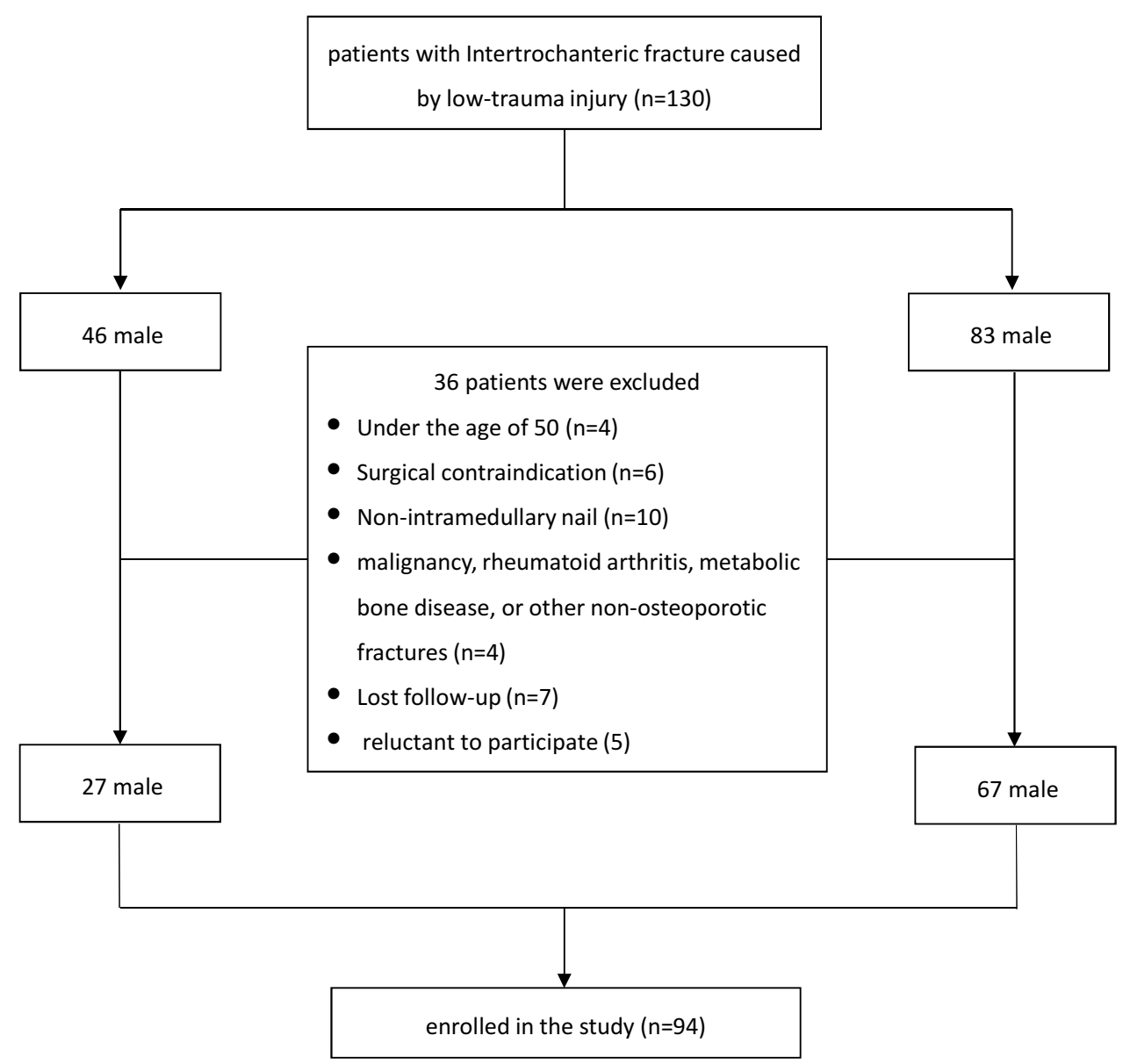

Figure I Flowchart for inclusion and exclusion of patients.

score, position of suffered limb, length of hospital stay, length of nail, and the entry point of nail were collected. Complications were recorded during the follow-up. The fracture types were described by $\mathrm{AO}$ classification, ${ }^{14}$ and the X-ray and CT imaging data were evaluated by two senior attending surgeons respectively. Two weeks later, the evaluation was repeated. If the result was consistent with the previous one, the fracture types were adopted as the final result. If the results were inconsistent, it was determined by a chief surgeon. The bone quality was assessed by the Singh index ${ }^{15}$ of the uninjured hip. Reduction quality was evaluated using the criteria established by Baumgaertner et al. ${ }^{16}$ The tip apex distance (TAD) ${ }^{17}$ was used to evaluate the implant position. The entry point of the nail was measured on the postoperative plain film of lateral view. According to the axis of nail in the position of the proximal femoral medullary cavity, the anterior $1 / 3$ was defined as anterior, the middle was defined as medial, and the posterior $1 / 3$ was defined as posterior. ${ }^{8}$

\section{Statistical Analyses}

SPSS (22.0 version, IBM Corporation, Armonk, NY) statistical software was used for data analysis. A descriptive analysis of the variables was performed and its results were expressed as percentages and proportions, or mean with standard deviation (mean $\pm \mathrm{SD})$. The univariate significance of the comparison between the impinged and matched group was established through $t$-test for continuous variables and $\chi^{2}$-tests for categorical variables. Risk factors for anterior cortical impingement were expressed by OR and 95\% confidence intervals (CI) through logistic regression. $P<0.05$ was defined as significant in all tests.

\section{Results}

\section{Baseline Characteristics}

Ninety-four patients were included for analysis, including 27 (28.7\%) males and 67 (71.3\%) females. The age ranged from 52-97 years, with an average age of $79.99 \pm 9.35$, and the mean follow-up was 8.7 months. Baseline characteristics of 
patients divided into impinged and matched group are presented in Table 1. The number of elderly female patients with intertrochanteric fractures was significantly higher than that of male patients, and the number of anterior cortical impingement complications is also significantly higher than that of male patients ( $80.4 \%$ vs $18.6 \%$ ). Other parameters, including age, suffered limb, height, weight, and BMI showed no difference between the two groups, and the same after gender stratification.

\section{Differences between Two Groups of Clinical and Radiographic Parameters}

By comparing the two groups of clinical and radiographic parameters, we found that the length of nail was significantly different (Table 2). The lngth of nail in the impinged group was much longer than the matched group. Further analysis revealed that nails with a length of more than $200 \mathrm{~mm}$ were used significantly more in the impinged group $(96.2 \%$ vs $73.3 \%)$, while nails with a length of more than $240 \mathrm{~mm}$ accounted for a higher proportion (22.6\% vs $6.6 \%$ ). Other parameters including the entry point, ASA score, Singh index, fracture types, reduction quality, implant types, length of stay, and

Table I Baseline Characteristics among Patients with Impinged and Matched Group (Mean \pm SD)

\begin{tabular}{|c|c|c|c|}
\hline Parameters & $\begin{array}{l}\text { Impinged } \\
\text { Groups }(n=5 I)\end{array}$ & $\begin{array}{l}\text { Matched } \\
\text { Groups }(n=43)\end{array}$ & $P$-value \\
\hline Gender & & & $0.04 I^{*}$ \\
\hline Male & $10(19.6 \%)$ & 17 (39.5\%) & \\
\hline Female & $4 \mathrm{I}(80.4 \%)$ & 26 (60.5\%) & \\
\hline Age (years) & $80.12 \pm 10.42$ & $79.88 \pm 8.44$ & 0.905 \\
\hline Male & $80.18 \pm 9.61$ & $78.70 \pm 6.83$ & 0.646 \\
\hline Female & $80.08 \pm 11.10$ & $80.17 \pm 8.45$ & 0.971 \\
\hline \multicolumn{4}{|l|}{ Suffered limb } \\
\hline Left & $24(47.1 \%)$ & 21 (48.8\%) & 0.514 \\
\hline Right & 27 (52.9\%) & $22(51.2 \%)$ & \\
\hline Height (cm) & $1.62 \pm 0.07$ & $1.6 \mathrm{I} \pm 0.07$ & 0.511 \\
\hline Male & $1.68 \pm 0.05$ & $1.71 \pm 0.05$ & 0.207 \\
\hline Female & $1.58 \pm 0.05$ & $1.59 \pm 0.05$ & 0.676 \\
\hline Weight (kg) & $60.76 \pm 13.10$ & $61.14 \pm 12.74$ & 0.887 \\
\hline Male & $63.15 \pm 9.56$ & $66.50 \pm 9.71$ & 0.395 \\
\hline Female & $59.19 \pm 14.93$ & $59.83 \pm 13.14$ & 0.859 \\
\hline BMI $\left(\mathrm{kg} / \mathrm{m}^{2}\right)$ & $23.12 \pm 4.74$ & $23.63 \pm 4.95$ & 0.615 \\
\hline Male & $22.40 \pm 3.38$ & $22.77 \pm 2.94$ & 0.772 \\
\hline Female & $23.57 \pm 5.47$ & $23.84 \pm 5.34$ & 0.775 \\
\hline
\end{tabular}

Note: *Statistical significance was considered when $P<0.05$.

Abbreviation: BMI, body mass index.
Table 2 Difference between Two Groups of Clinical and Radiographic Parameters (Mean \pm SD)

\begin{tabular}{|c|c|c|c|}
\hline Parameters & $\begin{array}{l}\text { Impinged } \\
\text { Groups }(n=5 I)\end{array}$ & $\begin{array}{l}\text { Matched } \\
\text { Groups }(n=43)\end{array}$ & $P$-value \\
\hline $\begin{array}{l}\text { Percentage of nail length } \\
\qquad 170 \\
200 \\
240\end{array}$ & $\begin{array}{l}2(3.8 \%) \\
39(73.6 \%) \\
12(22.6 \%)\end{array}$ & $\begin{array}{l}12(26.7 \%) \\
30(66.7 \%) \\
3(6.6 \%)\end{array}$ & $0.00 I^{*}$ \\
\hline $\begin{array}{l}\text { Entry point } \\
\text { Anterior } \\
\text { Middle } \\
\text { Posterior }\end{array}$ & $\begin{array}{l}2(3.9 \%) \\
38(74.5 \%) \\
I 1(21.6 \%)\end{array}$ & $\begin{array}{l}3(7.0 \%) \\
35(81.4 \%) \\
5(11.6 \%)\end{array}$ & 0.386 \\
\hline $\begin{array}{l}\text { ASA score } \\
\text { I } \\
\text { II } \\
\text { III } \\
\text { IV }\end{array}$ & $\begin{array}{l}18(35.3 \%) \\
17(33.3 \%) \\
10(19.6 \%) \\
6(11.8 \%)\end{array}$ & $\begin{array}{l}14(32.6 \%) \\
13(30.2 \%) \\
11(25.6 \%) \\
5(11.6 \%)\end{array}$ & 0.92 \\
\hline $\begin{array}{l}\text { Singh index } \\
\text { I } \\
\text { II } \\
\text { III } \\
\text { IV } \\
\text { V }\end{array}$ & $\begin{array}{l}22(43.1 \%) \\
15(29.4 \%) \\
6(11.8 \%) \\
6(11.8 \%) \\
2(3.9 \%)\end{array}$ & $\begin{array}{l}23(53.5 \%) \\
10(23.3 \%) \\
3(6.9 \%) \\
5(11.6 \%) \\
2(4.7 \%)\end{array}$ & 0.837 \\
\hline $\begin{array}{l}\text { Fracture classification } \\
\text { Type of AI } \\
\text { Type of A2 } \\
\text { Type of A3 }\end{array}$ & $\begin{array}{l}13(25.5 \%) \\
36(70.6 \%) \\
2(3.9 \%)\end{array}$ & $\begin{array}{l}14(32.6 \%) \\
25(58.1 \%) \\
4(9.3 \%)\end{array}$ & 0.364 \\
\hline $\begin{array}{l}\text { Reduction quality } \\
\text { Good } \\
\text { Acceptable } \\
\text { Poor }\end{array}$ & $\begin{array}{l}23(45.1 \%) \\
21(41.2 \%) \\
7(13.7 \%)\end{array}$ & $\begin{array}{l}20(46.5 \%) \\
19(44.2 \%) \\
4(9.3 \%)\end{array}$ & 0.799 \\
\hline $\begin{array}{l}\text { Implantation } \\
\text { PFNA } \\
\text { Intertan } \\
\text { TFNA } \\
\text { Gamma3 } \\
\text { TAD (mm) } \\
\text { Length of stay (days) } \\
\text { Implantation failure }\end{array}$ & $\begin{array}{l}43(84.3 \%) \\
2(3.9 \%) \\
5(9.8 \%) \\
1(2 \%) \\
21.08 \pm 5.61 \\
11.17 \pm 15.59 \\
7(13.7 \%)\end{array}$ & $\begin{array}{l}36(83.7 \%) \\
5(11.6 \%) \\
2(4.7 \%) \\
0(0 \%) \\
21.45 \pm 7.14 \\
8.79 \pm 3.02 \\
1(2.3 \%)\end{array}$ & $\begin{array}{l}0.33 \\
0.781 \\
0.067\end{array}$ \\
\hline
\end{tabular}

Note: *Statistical significance was considered when $P<0.05$.

Abbreviations: PFNA, proximal femoral nail antirotation; TFNA, trochanteric femoral nail antirotation; TAD, tip apex distance.

implant failure showed no difference between impinged and matched groups. However, the ratio of poor reduction and implant failure were higher in the impinged group. There were seven patients (13.7\%) with implant failure in the impinged group, with only one patient $(2.3 \%)$ in the matched group. Typical periprosthetic femoral fracture a month postoperatively are shown in Figure 2 and another developed cut out of the lag screw a year after the operation is shown in Figure 3. Then, male and female 

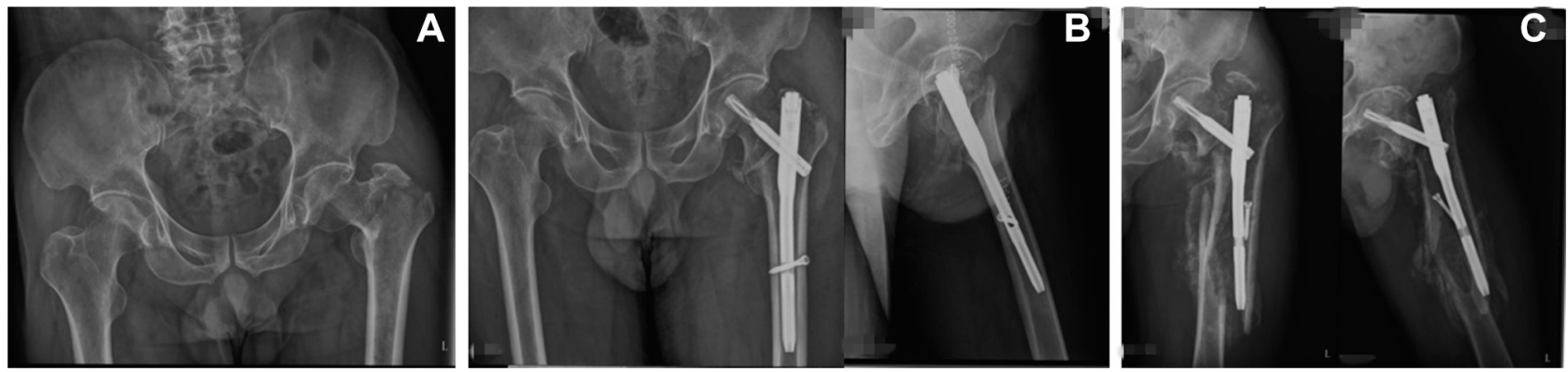

Figure 2 (A) Preoperative X-ray showing intertrochanteric fracture. (B) Postoperative X-ray showing poor reduction, the lateral position shows that the anterior cortex of the femur was obviously cortical encroachment. (C) One month later, the patient fell down resulting in fracture around the intramedullary nail of the femoral shaft.
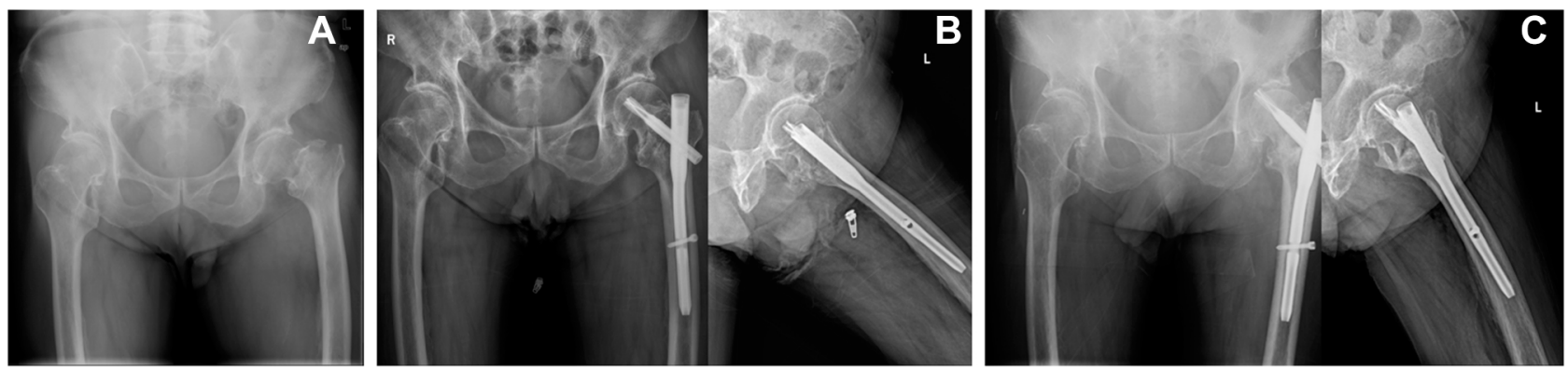

Figure 3 (A) Preoperative X-ray showing intertrochanteric fracture. (B) Postoperative X-ray showing reduction was acceptable. The lateral position showed the anterior cortex of the femur was obviously cortical encroachment. (C) The cut out of lag screw was found at one year of postoperative follow-up.

subgroups were assessed again, and similar results were observed only in the female subgroup (Tables 3 and 4), $97.6 \%$ of nails were longer than $200 \mathrm{~mm}$ in the impinged group.

\section{Risk Factors for Anterior Cortical Impingement in Intertrochanteric Fractures}

Through multi-factor logistic regression analysis, gender (as a female patient) and length of nail were significant risk factors for anterior cortical impingement in intertrochanteric fracture patients treated with intramedullary nail $(\mathrm{OR}=2.662,95 \%$ $\mathrm{CI}=1.010-7.018, P=0.447 ; \mathrm{OR}=1.047,95 \%$ CI $=1.016$ 1.079 , respectively). Gender was separated and then analyzed, and we found that only the length of nail was a risk factor for anterior cortical impingement in female intertrochanteric fracture patients treated with an intramedullary nail $(\mathrm{OR}=1.051$, 95\% CI $=1.015-1.089$ ) (Table 5).

\section{Discussion}

Anterior cortical impingement is a common phenomenon after intramedullary fixation in Asian patients with intertrochanteric fractures. ${ }^{12,13,18,20,21}$ Chang et al $^{13}$ reviewed 158 Chinese patients and found that the incidence of anterior femoral cortical impingement was $34.8 \%$. In this study, we found that anterior cortical impingement is popular in Chinese elderly patients with intertrochanteric fracture stabilized with an intramedullary nail. The incidence of anterior cortical impingement was $54.3 \%$, and more frequent in females, with an incidence of $80.4 \%$. The implant failure rate was higher in the impinged group. Hence, to explicit anterior cortical impingement of related risk factors is very important to patient treatment strategies.

Based on our findings, the length of nail and being female are the risk factors for the anterior cortical impingement. The majority $(54.3 \%)$ of the patients suffered from femoral anterior cortical impingement and the incidence of cortical impingement increased as the length of short nail (from $170 \mathrm{~mm}$ to $240 \mathrm{~mm}$ ) increased. This result is consistent with previous research, 120 patients with hip fracture underwent a CT scan and 3D reconstruction in Zhang et al $^{18}$ research, and the incidences of anterior cortical impingement were $71.4 \%, 77.4 \%$, and $80 \%$ in 170-mm, 200-mm, and 240-mm groups, respectively. Results from our previous research revealed greater femoral curvature and longer femoral bone marrow cavity isthmus in the Chinese population. ${ }^{11}$ However, available short nails are mainly straight designs. ${ }^{18}$ Therefore, as the 
Table 3 Comparison between Clinical and Radiographic Parameters among the Impinged and Matched Group in Male Patients (Mean \pm SD)

\begin{tabular}{|c|c|c|c|}
\hline Parameters & $\begin{array}{l}\text { Impinged } \\
\text { Groups }(n=0)\end{array}$ & $\begin{array}{l}\text { Matched } \\
\text { Groups }(n=17)\end{array}$ & $P$-value \\
\hline $\begin{array}{l}\text { Percentage of nail length } \\
\qquad 170 \\
200 \\
240\end{array}$ & $\begin{array}{l}0 \\
9(90 \%) \\
I(10 \%)\end{array}$ & $\begin{array}{l}2(11.8 \%) \\
14(82.3 \%) \\
1 \text { ( } 5.9 \%)\end{array}$ & 0.506 \\
\hline $\begin{array}{l}\text { Entry point } \\
\text { Anterior } \\
\text { Middle } \\
\text { Posterior }\end{array}$ & $\begin{array}{l}1(10 \%) \\
6(60 \%) \\
3(30 \%)\end{array}$ & $\begin{array}{l}3(17.6 \%) \\
11(64.8 \%) \\
3(17.6 \%)\end{array}$ & 0.704 \\
\hline $\begin{array}{l}\text { ASA score } \\
\text { I } \\
\text { II } \\
\text { III } \\
\text { IV }\end{array}$ & $\begin{array}{l}4(40 \%) \\
4(40 \%) \\
I(10 \%) \\
I(10 \%)\end{array}$ & $\begin{array}{l}6(35.3 \%) \\
5(29.4 \%) \\
5(29.4 \%) \\
I(5.9 \%)\end{array}$ & 0.691 \\
\hline $\begin{array}{l}\text { Singh index } \\
\text { I } \\
\text { II } \\
\text { III } \\
\text { IV } \\
\text { V }\end{array}$ & $\begin{array}{l}5(50 \%) \\
4(40 \%) \\
1(10 \%) \\
0 \\
0\end{array}$ & $\begin{array}{l}9(52.9 \%) \\
3(17.6 \%) \\
2(11.9 \%) \\
3(17.6 \%) \\
0\end{array}$ & 0.391 \\
\hline $\begin{array}{l}\text { Fracture classification } \\
\text { Type of A1 } \\
\text { Type of A2 } \\
\text { Type of A3 }\end{array}$ & $\begin{array}{l}3(30 \%) \\
7(70 \%) \\
0\end{array}$ & $\begin{array}{l}2(11.8 \%) \\
13(76.4 \%) \\
2(11.8 \%)\end{array}$ & 0.31 \\
\hline $\begin{array}{l}\text { Reduction quality } \\
\text { Good } \\
\text { Acceptable } \\
\text { Poor }\end{array}$ & $\begin{array}{l}3(30 \%) \\
4(40 \%) \\
3(30 \%)\end{array}$ & $\begin{array}{l}6(35.3 \%) \\
9(52.9 \%) \\
2(11.8 \%)\end{array}$ & 0.496 \\
\hline $\begin{array}{l}\text { Implantation } \\
\text { PFNA } \\
\text { Intertan } \\
\text { TFNA } \\
\text { Gamma3 } \\
\text { TAD (mm) } \\
\text { Length of stay (days) } \\
\text { Implantation failure }\end{array}$ & $\begin{array}{l}10(100 \%) \\
0 \\
0 \\
0 \\
25.25 \pm 6.78 \\
18.70 \pm 34.94 \\
2(20 \%)\end{array}$ & $\begin{array}{l}14(82.3 \%) \\
2(11.8 \%) \\
1(5.9 \%) \\
0 \\
23.66 \pm 8.08 \\
7.65 \pm 3.12 \\
0\end{array}$ & $\begin{array}{l}0.607 \\
0.358 \\
0.128\end{array}$ \\
\hline
\end{tabular}

Abbreviations: PFNA, proximal femoral nail antirotation; TFNA, trochanteric femoral nail antirotation; TAD, tip apex distance.

nail length increases, the risk of impingement caused by nail tip will inevitably increase, which is consistent with the results of this study. So we can conclude that shorter intramedullary nails may be a more advantageous option for treatment of intertrochanteric fractures. Besides, being an older Chinese female was another significant risk factor, and the possible reason may be the difference in femoral morphology in older women. In a retrospective
Table 4 Comparison between Clinical and Radiographic Parameters among the Impinged and Matched Group in Female Patients (Mean \pm SD)

\begin{tabular}{|c|c|c|c|}
\hline Parameters & $\begin{array}{l}\text { Impinged } \\
\text { Groups }(n=4 I)\end{array}$ & $\begin{array}{l}\text { Matched } \\
\text { Groups }(n=26)\end{array}$ & $P$-value \\
\hline $\begin{array}{l}\text { Percentage of nail length } \\
170 \\
200 \\
240\end{array}$ & $\begin{array}{l}\text { I }(2.4 \%) \\
29(70.8 \%) \\
\text { II (26.8\%) }\end{array}$ & $\begin{array}{l}8(30.8 \%) \\
16(61.5 \%) \\
2(7.7 \%)\end{array}$ & $0.002 *$ \\
\hline $\begin{array}{l}\text { Entry point } \\
\text { Anterior } \\
\text { Middle } \\
\text { Posterior }\end{array}$ & $\begin{array}{l}\text { I (2.4\%) } \\
32(78.0 \%) \\
8(19.5 \%)\end{array}$ & $\begin{array}{l}0 \\
24(92.3 \%) \\
2(7.7 \%)\end{array}$ & 0.285 \\
\hline $\begin{array}{l}\text { ASA score } \\
\text { I } \\
\text { II } \\
\text { III } \\
\text { IV }\end{array}$ & $\begin{array}{l}14(34.1 \%) \\
13(31.7 \%) \\
9(22 \%) \\
5(12.2 \%)\end{array}$ & $\begin{array}{l}8(30.8 \%) \\
8(30.8 \%) \\
6(23.0 \%) \\
4(15.4 \%)\end{array}$ & 0.979 \\
\hline $\begin{array}{l}\text { Singh index } \\
\text { I } \\
\text { II } \\
\text { III } \\
\text { IV } \\
\text { V }\end{array}$ & $\begin{array}{l}17(41.5 \%) \\
11(26.8 \%) \\
5(12.2 \%) \\
6(14.6 \%) \\
2(4.9 \%)\end{array}$ & $\begin{array}{l}14(53.8 \%) \\
7(27.0 \%) \\
1(3.8 \%) \\
2(7.7 \%) \\
2(7.7 \%)\end{array}$ & 0.623 \\
\hline $\begin{array}{l}\text { Fracture classification } \\
\text { Type of A1 } \\
\text { Type of A2 } \\
\text { Type of A3 }\end{array}$ & $\begin{array}{l}10(24.4 \%) \\
29(70.7 \%) \\
2(4.9 \%)\end{array}$ & $\begin{array}{l}12(46.2 \%) \\
12(46.2 \%) \\
2(7.6 \%)\end{array}$ & 0.13 \\
\hline $\begin{array}{l}\text { Reduction quality } \\
\text { Good } \\
\text { Acceptable } \\
\text { Poor }\end{array}$ & $\begin{array}{l}20(48.8 \%) \\
17(41.4 \%) \\
4(9.8 \%)\end{array}$ & $\begin{array}{l}14(53.8 \%) \\
10(38.5 \%) \\
2(7.7 \%)\end{array}$ & 0.909 \\
\hline $\begin{array}{l}\text { Implantation } \\
\text { PFNA } \\
\text { Intertan } \\
\text { TFNA } \\
\text { Gamma3 } \\
\text { TAD (mm) } \\
\text { Length of stay (days) } \\
\text { Implantation failure }\end{array}$ & $\begin{array}{l}33(80.5 \%) \\
2(4.9 \%) \\
5(12.2 \%) \\
1(2.4 \%) \\
20.06 \pm 4.86 \\
9.32 \pm 3.42 \\
5(12.2 \%)\end{array}$ & $\begin{array}{l}21(80.8 \%) \\
4(15.4 \%) \\
1 \text { ( } 3.8 \%) \\
0 \\
19.99 \pm 6.18 \\
9.54 \pm 2.76 \\
1(3.8 \%)\end{array}$ & $\begin{array}{l}0.961 \\
0.782 \\
0.392\end{array}$ \\
\hline
\end{tabular}

Note: *Statistical significance was considered when $P<0.05$.

Abbreviations: PFNA, proximal femoral nail antirotation; TFNA, trochanteric femoral nail antirotation; TAD, tip apex distance.

analysis of 150 patients with proximal femoral fractures, Roberts et $\mathrm{al}^{8}$ found that low height and a large femoral bow were risk factors for anterior cortical impingement. There was a $49 \%$ likelihood of cortical impingement if the height was less than $160 \mathrm{~cm}$. Su et $\mathrm{al}^{11}$ found that femoral length and radius were smaller in femaless through further study of anatomical parameters. Female with lower height had a larger anterior bow of the femur, which leads to the 
Table 5 Risk Factors for Cortical Impingement by Logistic Regression

\begin{tabular}{|l|l|l|l|l|}
\hline & Parameter & Odds Ratio & 95\% Confidence Interval & P-value \\
\hline Total & Gender & 2.662 & $1.010-7.018$ & 0.0477 \\
& Length of nail & 1.047 & $1.016-1.079$ & 0.0031 \\
\hline Female & Length of nail & 1.051 & $1.015-1.089$ & 0.0053 \\
\hline
\end{tabular}

anterior cortical impingement between the nail tip and anterior cortex. Therefore, it may be beneficial to select shorter nails for elderly Chinese women with lower height if possible.

The rate of implant failure was high in the impinged group. Fractures related to a stress riser at the nail tip associated with cortical impingement have been reported, ${ }^{22}$ but only a few studies focused on the relationship between cortical impingement and implant failure. Mori et $\mathrm{al}^{21}$ retrospectively analyzed 169 patients with stable fractures, and found that anterior cortical impingement caused internal fixation failure and delayed fracture healing significantly. Similar results were observed in our study, the incidence of implant failure was significantly higher in the impinged group comparing with the matched group, as the failure rate of internal fixation in the cortical impinged group was 6-times higher than that in the matched group. It is proposed that stress concentration on the femoral cortex applied by the tip of the nail, which alters the mechanical environment around the nail, may be the reason of impingement related femoral fractures. Besides, with poor reduction, the force is transmitted to the cortex through the implant instead of the femur itself, which may cause fracture under minor injuries. Chen et $\mathrm{al}^{23}$ also reported that the existence of mismatch between the morphology of the femur and the implanted nail not only makes the operation more difficult, but also leads to serious implant related complications for patients. Therefore, it is crucial to pay more attention to the selection of appropriate intramedullary nail for elderly female patients, in order to facilitate intramedullary nail implantation and reduce complications.

Peña et $\mathrm{al}^{9}$ found that the posterior nail start site was an incidental factor related with cortical impingement. Roberts et $\mathrm{al}^{8}$ believed that the posterior entry point increases the angle at which the nail is inserted, leading to over contact between the nail and the anterior cortex of the femur. However, no significant difference was discovered in our study. The reason may account for the low proportion of poor entry point in our series. But the proportion of posterior start site in the impinged group was higher than that in the matched group. Hence, avoiding a posterior entry point is still suggested to reduce cortical impingement and implant failure.

There are some limitations in this study. The relatively small sample size and the nature of retrospective studies limits the level of evidence of our study. However, strict inclusion and exclusion criteria and complete follow-up ensured the high quality of the study data. In addition, the follow-up of the patients in this study is short, but the implant failure generally occurs within 3 months, and with the extension of follow-up, the number of patients lost to follow-up increased, which may affect the results. Therefore, we chose to follow up for at least 6 months, which not only ensured the response rate of follow-up, but also included all adverse results. Finally, this study is an observational study of risk factors, without quantified specific values, and further refinement is needed in future studies.

\section{Conclusion}

In conclusion, there is a high incidence of anterior cortical impingement in Chinese patients with intertrochanteric fracture stabilized with a short intramedullary nail, especially in females. Moreover, the intramedullary nail length is a risk factor for anterior cortical impingement. More implant failures were noticed in the cortical impinged group. In consideration of this issue, caution should be paid in the treatment with this specific population, including selection of nail length as well as the entry point.

\section{Ethical Approval}

Ethical approval was obtained by the ethics committee of the Ethics Review Board of Chinese PLA General Hospital.

\section{Informed Consent}

Written informed consent was obtained from all participants.

\section{Funding}

This work was supported by the PLA Major Project (AWS17J004), the Capital Health Research and 
Development of Special Grants (2016-1-5012), the National Natural Science Foundation of China (81702153).

\section{Disclosure}

The authors declare that they have no competing interests.

\section{References}

1. Li M, Lv HC, Liu JH, et al. Differences in bone mineral density and hip geometry in trochanteric and cervical hip fractures in elderly chinese patients. Orthop Surg. 2019;11(2):263-269. doi:10.1111/ os. 12456

2. Ren $\mathrm{Y}, \mathrm{Hu} \mathrm{J}, \mathrm{Lu} \mathrm{B}$, et al. Prevalence and risk factors of hip fracture in a middle-aged and older Chinese population. Bone. 2019;122:143-149. doi:10.1016/j.bone.2019.02.020

3. Yu J, Zhang C, Li L, et al. Internal fixation treatments for intertrochanteric fracture: a systematic review and meta-analysis of randomized evidence. Sci Rep. 2015;5:18195. doi:10.1038/srep18195

4. Morin S, Lix LM, Azimaee M, et al. Mortality rates after incident non-traumatic fractures in older men and women. Osteoporos Int. 2011;22(9):2439-2448. doi:10.1007/s00198-010-1480-2

5. Tang P, Hu F, Shen J, et al. Proximal femoral nail antirotation versus hemiarthroplasty: a study for the treatment of intertrochanteric fractures. Injury. 2012;43(6):876-881. doi:10.1016/j.injury.2011.11.008

6. Liu W, Zhou D, Liu F, et al. Mechanical complications of intertrochanteric hip fractures treated with trochanteric femoral nails. J Trauma Acute Care Surg. 2013;75(2):304-310. doi:10.1097/ TA.0b013e31829a2c43

7. Bazylewicz DB, Egol KA, Koval KJ. Cortical encroachment after cephalomedullary nailing of the proximal femur: evaluation of a more anatomic radius of curvature. J Orthop Trauma. 2013;27 (6):303-307. doi:10.1097/BOT.0b013e318283f24f

8. Roberts JW, Libet LA, Wolinsky PR. Who is in danger? Impingement and penetration of the anterior cortex of the distal femur during intramedullary nailing of proximal femur fractures: preoperatively measurable risk factors. J Trauma Acute Care Surg. 2012;73 (1):249-254. doi:10.1097/TA.0b013e318256a0b6

9. Peña OR, Gómez Gélvez A, Espinosa KA, et al. Cephalomedullary nails: factors associated with impingement of the anterior cortex of the femur in a Hispanic population. Arch Orthop Trauma Surg. 2015;135(11):1533-1540. doi:10.1007/s00402-015-2313-8

10. Chang S-M, Hu S-J, Ma Z, et al. Femoral intertrochanteric nail (fitn): a new short version design with an anterior curvature and a geometric match study using post-operative radiographs. Injury. 2018;49 (2):328-333. doi:10.1016/j.injury.2017.11.017
11. Su XY, Zhao JX, Zhao Z, et al. Three-dimensional analysis of the characteristics of the femoral canal isthmus: an anatomical study. Biomed Res Int. 2015;2015:459612.

12. Shin WC, Seo JD, Lee SM, et al. Radiographic outcomes of osteosynthesis using Proximal Femoral Nail Antirotation (PFNA) system in intertrochanteric femoral fracture: has PFNA II solved all the problems? Hip Pelvis. 2017;29(2):104-112. doi:10.5371/hp.2017.29.2.104

13. Chang S-M, Song D-L, Ma Z, et al. Mismatch of the short straight cephalomedullary nail (PFNA-II) with the anterior bow of the femur in an Asian population. J Orthop Trauma. 2014;28(1):17-22. doi:10.1097/BOT.0000000000000022

14. Marsh JL, Slongo TF, Agel J, et al. Fracture and dislocation classification compendium - 2007: orthopaedic Trauma Association classification, database and outcomes committee. J Orthop Trauma. 2007;21(10 Suppl):S1-S133. doi:10.1097/00005131-200711101-00001

15. Singh M, Nagrath AR, Maini PS. Changes in trabecular pattern of the upper end of the femur as an index of osteoporosis. J Bone Joint Surg Am. 1970;52(3):457-467. doi:10.2106/00004623-197052030-00005

16. Baumgaertner MR, Curtin SL, Lindskog DM. Intramedullary versus extramedullary fixation for the treatment of intertrochanteric hip fractures. Clin Orthop Relat Res. 1998;348:87-94. doi:10.1097/ 00003086-199803000-00015

17. Siegel RS. The value of the tip-apex distance in predicting failure of fixation of peritrochanteric fractures of the hip. J Bone Joint Surg Am. 1996;78(9):1447-1448.

18. Zhang S, Zhang K, Wang Y, et al. Using three-dimensional computational modeling to compare the geometrical fitness of two kinds of proximal femoral intramedullary nail for Chinese femur. ScientificWorldJournal. 2013;2013:978485.

19. Chon C-S, Kang B, Kim HS, et al. Implications of three-dimensional modeling of the proximal femur for cephalomedullary nailing: an Asian cadaver study. Injury. 2017;48(10):2060-2067. doi:10.1016/j. injury.2017.07.009

20. Schmutz B, Amarathunga J, Kmiec S Jr, et al. Quantification of cephalomedullary nail fit in the femur using 3D computer modelling: a comparison between 1.0 and $1.5 \mathrm{~m}$ bow designs. J Orthop Surg Res. 2016;11(1):53. doi:10.1186/s13018-016-0389-7

21. Mori CM, Vicenti G, Carrozzo M, et al. The fake unlocked femoral nail: a configuration to avoid in stable pertrochanteric femur fractures. Injury. 2018;49(Suppl 3):S32-S36. doi:10.1016/j.injury.2018.09.057

22. Robinson CM, Houshian S, Khan LAK. Trochanteric-entry long cephalomedullary nailing of subtrochanteric fractures caused by low energy trauma. J Bone Joint Surg Am. 2005;87:2217-2226. doi:10.2106/JBJS.D.02898

23. Chen F, Zhao Z, Gao C, et al. Clustering of morphological features for identifying femur cavity subtypes with difficulties of intramedullary nail implantation. IEEE J Biomed Health Inform. 2018;22 (4):1209-1217. doi:10.1109/JBHI.2017.2761980
Therapeutics and Clinical Risk Management

\section{Publish your work in this journal}

Therapeutics and Clinical Risk Management is an international, peerreviewed journal of clinical therapeutics and risk management, focusing on concise rapid reporting of clinical studies in all therapeutic areas, outcomes, safety, and programs for the effective, safe, and sustained use of medicines. This journal is indexed on PubMed Central, CAS,
EMBase, Scopus and the Elsevier Bibliographic databases. The manuscript management system is completely online and includes a very quick and fair peer-review system, which is all easy to use. Visit http://www.dovepress.com/testimonials.php to read real quotes from published authors. 